\title{
In search of healthy sexuality: the gap between what youth want and what teachers think they need
}

\author{
C BEYERS $S^{1}$
}

\begin{abstract}
The fact that youth between the ages of 15 and 24 are most vulnerable to contract HIV (UNAIDS, 2011) is a clear indication that adults are failing to provide them with the necessary skills and information to make informed decisions about healthy sexuality. Adults, including teachers, have a responsibility to engage youth about sexuality, in order to challenge critical thinking with the aim of contributing towards healthy and responsible individuals. Presently, sexuality education is taught as a component of Life Orientation, and teachers are given a considerable amount of autonomy on what and how to teach. This article aims to explore the gap between what youth want from sexuality education and what teachers think they need. I pose two questions: What are the sexuality education needs of youth? What do teachers think youth need in terms of sexuality education? To answer these questions, I argue that teachers seem to have knowledge on what youth need, but do not necessarily respond to what youth require in terms of sexuality education. Using an interpretive stance, I explore potential gaps and possible opportunities in how sexuality education is taught and discuss the need for a common agreement on, or understanding for the teaching and learning of sexuality education. I conclude with direction that future research might take.
\end{abstract}

Keywords: communication; sexuality; social network sites

\section{Introduction}

Teaching sexuality in South African schools has been the subject of discussion and debate for many years. The need for an adequate response to, and proper management of HIV/AIDS and sexuality education, are very important to the well-being of youth. The World Bank (2000) expands on this notion when stating that HIV and AIDS can wipe out developmental gains of a generation if it is not attended to in an appropriate way. The HIV and AIDS pandemic in South Africa is a clear indication that there is an "alarming failure of communication" between adults and youth with regards to sexual issues (Delius \& Glaser, 2002: 27). Francis and DePalma (2013) assert that there exist two pre-eminent stances in the teaching of sexuality: abstinence-only and comprehensive sexuality education. Abstinenceonly programmes teach that sexual activity outside a marriage is likely to have harmful consequences such as unwanted pregnancies, sexual transmitted infections (STI's) and HIV, sending a message that abstaining from sex is the only appropriate option. On the other hand, proponents of comprehensive sexuality education - that is education that views

Christa Beyers $(\mathrm{PhD})$ is a Lecturer in the School of Education Studies, University of the Free State. She is project manager of the Teaching and Learning about Sexuality and HIV/AIDS (TALSHA) project of the Faculty of Education, UFS and her research includes the use of Visual Participatory Methodology. E-Mail beyersc@ufs.ac.za 
abstinence as the best prevention strategy, but in addition provides accurate information on inter alia contraception, gender differences, safe and healthy sex and sexual pleasure - believe that sexuality education should assist youth in gaining appropriate knowledge and skills in order for them to develop a positive view of sexuality and make informed decisions about their sexual behaviour (Kirby, 2008; Eisenberg, Bernat, Bearinger \& Resnick, 2008). Although evidence strongly demonstrates the effectiveness of comprehensive sexuality education, research on sexuality and HIV/AIDS is still dominated by studies concerning the biomedical nature and unwanted consequences of sexuality (Kirby, Laris \& Rolleri, 2005; Blake, 2008). Knowledge valued by adults is usually prescriptive to 'keep youth safe', without taking into consideration the sexual experiences of young people and what information they need (Allen, 2001). Strange, Forrest, Oakley, Stephenson and the RIPPLE study team (2006) have identified factors that influence the quality of sexuality education. These include lack of time available for planning and delivery; teachers' lack of confidence and commitment; feelings of embarrassment; and lack of training. Francis (2010) and Beyers (2011) concur by stating that teachers are unwilling to engage in dialogues, because they themselves do not feel comfortable in the teaching of sexuality. These difficult dialogues cannot be ignored because, if we do not acknowledge youth's own sexual knowledge and needs, young people may feel alienated from the messages of sexuality education. However, there is no doubt that youth obtain sex information somewhere. Society is awash with depictions of sexuality, whether it is on television, the internet or in magazines. The question should be asked as to whether this is the information to which we want to expose youth. If we, as adults, do not talk about sex, we are surrendering the responsibility to peers and technology to which youth have access. Adults need to encourage dialogue with youth and try to establish what learners want to learn in sexuality education if they want to promote healthy sexuality. In theory, the Life Orientation curriculum should empower youth for their future lives. However, in practice, we need to address the inconsistent implementation, the content taught as well as the limited time spent on sexuality education nationwide.

The majority of sexuality programmes effect social change. When considering that youth may be more susceptible to influences that could help them reflect on attitudes, beliefs and behaviour when they themselves are involved (Winkleby, Feighery, Dunn, Kole, Ahn \& Killen, 2004), it is clear that there is a need for social innovation. The latter concerns the application of new ideas or the reapplication of existing ideas in novel ways, in order to add value to, and impact on social issues such as HIV and sexuality. Although sexuality is fundamental to the development of the youth, understanding the latter's needs is still an essential step towards healthy sexuality. Aggleton (1997) emphasised this, stating that the answer to what and how to teach sexuality certainly lies within the youth themselves. Youth should find it easy and convenient to participate if we want to give them a voice to take part and become involved in their own fight against HIV and AIDS and to effect social change. Mankoff, Matthews, Fussel and Johnson (2007: 4) agree, stating that for youth to participate in social change movements, the activities should be "easily integrated into daily life". In support of this, South Africa experiences a continuing rise in the importance of social networks, especially in the lives of youth (IT NEWS Africa, 2012). Not only are social networks viewed as acceptable and personal, but youth value the informal language used. By making use of social networks such as Facebook, messages can be short, positive and cover a variety of topics with immediate feedback. Passy and Giugni (2001: 123) postulate that networks serve three purposes, namely "structurally connecting prospective participants to an opportunity to participate, socializing them to a protest issue, and shaping their decision to

TD, 9(3), Spec. ed., December 2013, pp. 550-560. 
become involved". In addition, youth are more likely to become involved in a discussion about HIV and sexuality if their peers are also involved. Social Networking Sites (SNS) are rapidly becoming a pervasive part of adolescent culture (Boyd \& Ellison, 2007), and are expanding more significantly than any other online modality, including e-mail (Nielsen, 2009). At least $75 \%$ of South African youth use some form of SNS (UNICEF, 2011). Among younger people, the use of cellular phones and internet SNS appear to be one of the most prevalent forms of communication. These strengthened networks can easily translate into strong knowledge tools when used in an appropriate manner. For adults communication technologies offer exciting opportunities to engage personally with a huge number of youth at minimum cost.

\section{The need to stay 'in touch'}

The interpretive perspective (Orlikowski \& Baroudi, 1991; Walsham, 1993) claims that individuals seek to construct their own knowledge of reality as they interact with the world in which they live and work. Thomas (2009) holds that the main point of interpretivism is that we are interested in people and the way they interrelate, what they think and how they form ideas about the world, and how these worlds are constructed. They develop subjective meanings of their own experiences about a variety of issues. Henning, Van Rensburg and Smit (2004:21) agree and state that "the interpretive paradigm does not concern itself with the search for broadly applicable laws and rules, but rather seeks to produce descriptive analyses that emphasize deep, interpretive understanding of social phenomena". When making use of multi-methods, as in this study, the researcher seeks a complexity of views rather than restricting the meanings into a few categories or ideas. The participants are thus given the opportunity to construct their own meaning of certain issues - in this study, what youth want with regards to sexuality education, and what teachers think they need. The meanings that individuals attach to certain issues cannot be viewed in isolation, as all human beings are influenced by the society and culture in which they were socialised. It should be mentioned that, when analysing the data, I as a researcher should be aware that my own experiences and socialisation could also influence data interpretation (Creswell, 2003). I concur with Henning et al (2004) who argue that one can never be free of bias in a qualitative study. The aim of this study was, however, not to find a universal truth, but to understand whether teachers teach content that youth need and want.

\section{Problem statement}

Taking into consideration that positive dialogue with regards to sexuality and HIV seems to be almost non-existent between adults and youth, the potential of comparing the voices of teachers and learners has a great deal to offer towards responsible sexual behaviour. Not only teachers, but also youth should be viewed as a large untapped resource with regards to HIV and sexuality education. Two questions arise: What are the sexuality needs of youth? What do teachers think youth need from sexuality education?

\section{Methodology}

I made use of a multi-methods qualitative research in an effort to understand what teachers think youth need from sexuality education, and to find out whether this correlates with what 
youth themselves need. I conducted a survey on Facebook with first-year students enrolled at CUT, and held group discussions with 125 Life Orientation teachers.

The students were invited to sign up via Facebook with the aim of identifying what their needs are with regards to sexuality education. In addition, three posters were displayed in visible positions to invite anyone interested in sexuality education to join. Two lecturers, both experts in sexuality issues, were involved with the aim to offer a platform for discussing what youth want from sexuality education. Students were invited to join the public Facebook profile by choosing the 'like' option. They were then connected to participate in the forum and could read all the questions, make comments and share ideas. Thirty-seven students took part in answering the posed questions, and initial answers and comments led to students asking subsequent questions. The reason for making use of Facebook as tool is that Facebook is believed to be the new 'mall' - a place where youth go to hang out and socialise (UNICEF, 2011). In addition, Facebook claims 200 million active users and estimates that their users spend 3.5 billion minutes on Facebook daily (Facebook, 2009). By making use of Facebook as SNS, a collaborative approach is employed: experts can become involved in disseminating information, and youth can share knowledge and ideas that could assist in social change. Accessibility of knowledge through social media must be viewed as an obvious choice - most youth have access to the internet, not to mention cellular phones which $72 \%$ of youth are reported to own (UNICEF, 2012). By creating a SNS forum, youth could be assisted in critical thinking skills which may lead to reflection on the individual and society, self/others, democratic culture and notions of equality/inequality (Rogow \& Haberland, 2005).

I initially posed the following questions: What were you taught in sexuality education, and by whom? What information would you like to obtain?

The focus group discussion is the result of a collaborative workshop facilitated by researchers from the University of the Free State with the attendees being teachers from the Free State Department of Education. The sample was purposive insofar as all the educators, registered for a sexuality education workshop, also teach Life Orientation at the senior level (Grades 7 to 10). The teachers were diverse in terms of race, gender, class, ethnicities and age. My reference to race draws on the nomenclature of South Africa's apartheid past and should not, as stated by Francis \& DePalma (2013:12), "lend credibility to popular stereotypes that accompany these descriptors". It is important to note that the teachers taught in a range of schools, from urban to rural, with differing socio-economic contexts. The group discussion was unstructured, in order to elicit the participants' true feelings and perceptions regarding their own conceptualization of healthy sexuality. During this discussion, the following questions were posed: What do you think young people want from sexuality education? How do they want to be taught?

The rationale behind these methods is to add to the trustworthiness of the study which is underpinned by the principle of triangulation (Strauss \& Corbin, 1998). This implies that I do not rely solely on one group of participants when a second group can enrich the data. According to Morse \& Field (1998: 130), each piece of data must be compared with every other piece of relevant data. This could be viewed as a challenge and be criticised as only the researcher decides which data is relevant. During the analysis, the two groups' data were transcribed, thus providing the input for the process of analysis. The analysis consisted of the two activities, as described by Dey (1993), namely fragmenting and connecting. The process of fragmenting should be viewed as analysing two sets of data and then seeking themes that can connect the data. According to Boeije (2002), it is important to pose the following 
questions: What do the two groups say about the issue? Which themes appear in one group, but not in the other, and vice versa? Why do both groups view issues differently or similarly? What additional information can be derived from one group about the other group? This step is aimed at identifying the gaps that might exist between teachers and youth about sexuality education. Furthermore, the purpose of making use of a multi-method approach was to place participants at the centre of data analysis. De Lange, Mnisi and Mitchell (2010) make it clear that by making use of participatory methods such as Facebook and collaborative workshops, the participants are given a voice to identify key issues as well as challenges that affect their lives, instead of being the recipients of what is valued 'knowledge' by researchers.

Burns and Grove (2001) emphasise that, for ethical purposes, the rights of both the researcher and the participants should be protected. The research project, under which the workshop intervention is located, served and was approved by the Faculty of Education Ethics Committee at the University of the Free State. All protocols were followed as participants were informed of the intention to use all available data for research purposes. Participants were informed of the intention to use all available data for research purposes. They were also given the choice to take part in all activities. All participants could withdraw from the study at any time.

\section{Limitations}

This study proved to be an interesting and revealing journey, but not without limitations, especially on SNS. Initially, a great deal of time was spent on keeping the discussions on Facebook live, vibrant, engaging and flowing. The facilitator has to be involved and make meaningful input. This topic must be carefully monitored, as sexuality and HIV could lead to rash comments. This study started on a small scale - using only Facebook with a small group of students. The ideal is to create a network to involve youth from diverse backgrounds who can reach out and share knowledge. Although the advantages are apparent, demographic groups who do not have access to computers or smart phones are still a cause for concern.

\section{Discussion of findings}

The initial responses made it clear that the truth held by one person does not necessarily hold true for another. The comments were divided into categories and discussed in themes identified by the researcher. This report will not focus on whether the research questions have been answered, but rather on the respondents' interesting responses, comments and questions. Based on the analysis of the two sets of data, the views of the youth were juxtaposed with those held by the teachers towards a holistic picture of what might be the cause of the gap between what teachers think youth want and what they need. I will, therefore, distinguish between the views of teachers $(\mathrm{T})$ and those of youth $(\mathrm{Y})$. Where applicable, I will cite relevant literature to add to the value of the discussion (Cresswell, 2008: 90).

\section{Theme 1: Open communication}

In an effort to improve sexuality education with the aim of inter alia reducing teenage pregnancy rates and minimizing the contraction of STI's, it is imperative to evaluate the sexuality education offered to youth in South Africa. Although some teachers believe that their responsibility lies in being role models to the youth they teach, it appeared that the majority of them are aware that youth need to talk about sex and sexuality and that they have 
to be taught "the truths and facts about sexuality" (T). Teachers agreed that youth need "openness to discuss sexuality issues with each other and adults" ( $T)$, but they did not feel comfortable to address all issues that youth may need with respect to healthy sexuality. This concurs with the view of Delius and Glazer (2002) that adults find it difficult to broach the issue of sex with youth. The reality therefore remains that youth have little option but to search for information elsewhere, frequently from peers and the internet. The majority of the youth participants concurred with the teachers' view, as they reported that they need to communicate about sexuality, but that their parents and teachers seldom wanted to talk about sexual issues in which they were interested and, if they did communicate, it was about abstaining.

Most teacher participants believe that teaching values, responsibilities and cultural norms are of utmost importance in sexuality education. Culture and religion should be viewed as a valid concern, as we are all shaped by our culture and life experiences, and our behaviour is determined by what we are taught (Wood, 2008). Although a few youth participants reported that they would feel comfortable if the sexuality educator were of a similar cultural background, and share similar moral and religious beliefs as themselves, it must be noted that one youth participant mentioned that it is sometimes embarrassing to discuss certain topics if the educator is someone they knew, from their own community, as s/he believed that to obtain information from people who think alike could hamper his/her own sexuality. "We will never get the chance to experiment" $(Y)$. This should be an indication that youth have an understanding of the pleasures of sex, but that they are of the opinion that they should not share some aspects with adults, as adults still seem to focus on what they themselves find acceptable from their own moral and religious perspectives. The problem is that many of the youth participants reported that they have not received sufficient knowledge regarding sex education. To initiate effective communication, it is important that there is a relationship of mutual trust. Although teachers acknowledge that they should not be judgemental, it has become clear that they do not feel comfortable in addressing what Allen (2004) calls the discourse of desire. One should ask the question whether teachers do not shy away from talking about important issues, as they mentioned that youth want to be taught by peereducators so that "they can feel comfortable and free" (T). One teacher mentioned that they "want reality because they already know everything", giving the impression that adults cannot meet the needs of youth, as they are already sexually active.

Despite considerate efforts to include sexuality education into the Life Orientation curriculum, high-risk sexual behaviour seems to remain the norm for many adolescents. Furthermore, the stigma associated with STI's contributes to the silence as experienced by both teachers and learners. If youth are given a voice, the outcome could be positive: it could offer teachers and youth an exciting opportunity to engage in difficult, but crucial dialogues.

\section{Theme 2: Content}

It appears that adults undertake sexuality education without keeping in touch with the changes that have occurred over the last decades in the social construction of sexuality. Connell and Dowsett (1992) have made it clear that conventional ideas about sexuality are continuously challenged. The HIV and AIDS pandemic in South Africa is one of the major challenges which focussed the attention on how, where and what youth learn about sex. When the focus groups were asked what information they think youth need, one of the participants mentioned that youth need accurate information that will help them to be 
healthy and responsible. When asked what the participant meant with 'accurate information', the teachers stated that youth need to know the "consequences of sexuality" and should be taught to have "boundaries". They also acknowledged that they feel comfortable in teaching the biomedical dimensions of sexuality as well as religion and values. Teachers made it clear that they believe that to teach biological and developmental facts such as the age of the onset of menstruation, nocturnal emissions, and so on are very important. Although this is true, there is little value in teaching this content after these events have already happened. The same applies to sex and sex-related experiences - youth should be informed before they become sexually involved.

Most teacher groups included the need for teaching about sexually transmitted infections (STIs) and the use of contraceptives. One group mentioned that youth must be taught "what is good and what is bad" (T), which could be categorised under the "abstinence-only-untilmarriage" programme, as discussed by the Advocates for Youth: Towards a Sexually Healthy America (2001). It appears that teachers shy away from the comprehensive model where sexuality is viewed as "a natural, normal and healthy part of life". Most of the youth who joined on Facebook were of the opinion that all individuals must be aware of the high HIV/AIDS rate in South Africa, and thus not add to the pandemic, but act pro-actively. Comments to achieve this included: “... teach us safe sex methods, not only abstain" (Y); "That is what we are taught ... ABC. It does not work for the youth" (Y), and "They can be open and say ... masturbate - alone and mutual" (Y).

One teacher mentioned that youth believe that they need to be sexually active in order to be accepted by their peers. They, therefore, need to be taught to be assertive and how to deal with emotions such as "where to get help after a sexual encounter" $(T)$. This in itself seemed to accentuate that many adults work from a negative discourse, rather than focusing on the positive and healthy aspects of sexuality. This correlates with literature findings that sexuality education focuses on medical and disease discourse rather than on an erotic one (Allen, 2004).

Following a discussion between the members of a focus group, one of the teacher participants mentioned that youth must be taught "what the Bible says about sexuality" (T). It was also emphasized that youth need to be taught responsibility and respect for one another. Although this might be a valid point, the teachers appeared to be afraid to be frank about exactly what was meant by that remark. This could create a gap, as one youth participant $(\mathrm{Y})$ mentioned that "adults want us to obey laws and refrain from sexual relationships". The majority of the youth participants agreed and added that they are taught about sexually transmitted diseases and HIV: "We are not informed, we are warned" $(\mathrm{Y})$. The interaction initiated by this comment between youth participants was valuable. The following comments illustrate this: "... it seems as if sex is just bad news which we should be afraid of" (Y); “... how can having sex be bad news? It is meant to be enjoyable" (Y), and "... I think he means that one must only think of the consequences, which could end up being bad news - LOL” (Y).

The youth's comments indicate that adults emphasise the negative consequences of sexuality, and that they need to follow rules. This ignores the realities of the social and emotional aspects of sexuality. One should perhaps take note of Fine \& McClelland's (2006) argument that youth's development into healthy sexual beings will be compromised if there are no critical conversations about sexuality in schools.

All the focus groups (teachers) agreed that youth need honest information about issues such as relationships and 'chemistry' between people, but it was again emphasised that youth must 
be taught about the negative consequences of having sexual relationships. One group made it clear that youth want to know what the difference is between sex and sexuality, as they "want to experiment" (T). This concurs with findings from research by Goldman (2008) who found that adults assume that youth will engage in promiscuous sexual behaviour if they obtain information on sexual issues. Teachers are aware that youth are most probably insecure about their own sexuality, as one group mentioned that youth need information, because "they want to know if their experiences are the same as others". Youth want to know whether adults faced similar sexual challenges to those that youth are currently facing. The reality exists that there are high levels of sexual activity amongst youth, and if teachers are not willing or able to confront what they view as awkward, youth are left to conseptualize sexuality on their own.

Theme 3: Mode of delivering sexual messages

Advances in technology have dramatically changed how people, especially youth, communicate and access information. The time has come for widespread recognition of a different approach needed to teach sexuality. The ideal, according to Shön (1983), is for all teachers to be reflective practitioners, implying that they should reflect on their own teaching as well as analyse and engage in a process of continuous learning. Evans and Policella (2000: 62) add that 'reflection requires teachers to be introspective, open-minded, and willing to be responsible for decisions and actions'. It may be time for teachers to take to heart what Francis and Ingram-Starrs (2005: 551) express: 'those [voices] we ignore have more to teach us'. During the workshop with teachers, one participant made an interesting remark: youth need information from adults, because "they believe what they learn in the media and through friends" $(\mathrm{T})$. This serves as a reminder that teachers are aware that youth obtain information from social networks, the internet and friends. If teachers do not capitalise on this reality, it could increase the gap in the teaching of sexuality. The youth's comments on Facebook emphasised the validity of these remarks. One participant reported (and it was echoed by others) that s/he knows many youths who watch pornography, but it is "unhealthy and becomes a problem - especially on cell phones" $(\mathrm{Y})$. During this discussion, which came about by posting another question, youth participants were of the opinion that students watch this because they are curious, and they did not obtain "any information from anybody" $(\mathrm{Y})$. Other participants disagreed that it was a problem, and viewed it as 'normal'. Comments related to pornography on cellular phones and 'sexting', included: “... I get some visual material on my phone, which gives me plastic information”, and “... phones can assist uninformed youth to see and hear new things" (Y).

These comments clearly indicate that there is a need for knowledge on all aspects of sexuality. Zisser \& Francis (2006) acknowledge 'non-formal' sources of information as critical in encouraging healthy sexuality amongst youth; therefore making use of SNS must be regarded as a new and novel approach to talk about sexuality, but more important, talk about what youth need. The value of sharing thoughts on Facebook is that feedback could be immediate and, when used by adults, could give informed information. Teachers mentioned that they must communicate on the level of youth, and that youth should be allowed "to express their own views" (T). Making use of SNS could answer this call, as youth are comfortable in the use of technology, and might just believe that it is easier to ask relevant questions without the possibility of feeling ashamed in front of peers. In fact, even teachers could feel more comfortable talking freely about issues they themselves avoid.

I also found the comments between youth participants precious - they became involved and attempted to inform and answer questions posed by fellow participants. Becoming involved 
with peers from diverse backgrounds could help create social awareness and social network sites may afford them the opportunity to share their thoughts on certain issues such as masturbation and fondling which teachers are not comfortable in discussing. One of the teacher participants mentioned that youth should be taught in a language that they understand - it appears that the youth participants prefer the SNS as that language.

\section{Conclusion}

This paper aimed to establish whether there is still a gap between what teachers teach and what youth need from sexuality education. While the data discussed suggests that teachers do have knowledge of what youth need with regards to sexuality education, it still appears that sexuality is viewed as a private matter - meant for adults only. Data reveals that there is an urgent need for positive dialogue, as emphasised not only by teachers involved in the teaching of sexuality education, but also by youth. Teachers have no problem with teaching the 'disease discourse' where the focus is on negative consequences such as STI's and HIV, but when it comes to addressing the youth's needs, they shy away. I argue that, if adults do not teach content that youth need, it may compromise the sexual health of youth, as it became clear from the data that youth do find information that they want on SNS. Teachers (and parents) should ask themselves whether this information is sufficient to add to the development of healthy individuals. During the group discussions, teachers mentioned that youth need to be taught by making use of "modern techniques" such as DVDs and TV series. This implies that teachers understand the need for novel methods to be used in a classroom situation. By making use of SNS, teachers could address issues in a controlled setting without exposing themselves or youth, and at the same time add to sexual health and well-being. It appears that there is a need for agreement between all stakeholders when teachers decide on what and how to teach in order to be of mutual benefit towards a sexual healthy society.

\section{References}

Advocates for Youth. 2001. Towards a sexually healthy America. Roadblocks imposed by the Federal Government's Abstinence-Only-Until-Marriage Education Program. www.advocatesforyouth.org. Accessed on 20 August 2013.

Aggleton, P. 1997. Success in HIV prevention. Some strategies and approaches. London: Avert.

Allen, L. 2004. Beyond the birds and the bees: Constituting a discourse of erotics in sexuality education. Gender and Education, 16(2): 151-167.

Allen, L. 2001. Closing sex education's knowledge/practice gap. The reconceptualization of young people's sexual knowledge. Sex Education, 1(2): 109-122.

Beyers, C. 2011. Sexuality education in South Africa: A socio-cultural perspective. Acta Academica 43(3): 192-209.

Blake, S. 2008. There's a hole in the bucket: The politics, policy and practice of sex and relationships education. Pastoral Care in Education, 26(1): 33-41.

Boeije, H.R. 2002. A purposeful approach to the constant comparative method in the analysis of qualitative interviews. Quality E Quantity 36(4): 391-409.

Boyd, D.M. \& Ellison, N.B. 2007. Social network sites: Definition, history, and scholarship. Journal of Computer-Mediated Communication, 13(1): 210-230. 
Connell, R.W. \& Dowsett, G.W. 1992. Rethinking sex: Social theory and sexuality research. Carlton, Vic: Melbourne University Press.

Cresswell, J.W. 2003. Research design. Qualitative, quantitative and mixed methods approaches. $2^{\text {nd }}$ ed. London: Sage.

Delius, P. \& Glaser, C. 2002. Sexual socialization in South Africa: a Historical Perspective. African Studies, 61(1): 27-54.

Dey, I. 1993. Qualitative data analysis. A user friendly guide for social scientists. London: Routledge.

De Lange, N., Mnisi, T. \& Mitchell,C. 2010. Giving life to data: University-community partnerships in addressing HIV and AIDS through building digital archives. ELearning and Digital Media, 7(2), 160-171.

Eisenberg, M.E., Bernat, D.H., Bearinger, L.H. \& Resnick, M.D. 2008. Support for comprehensive sexuality education: Perspectives from parents of school-age youth. Journal of Adolescent Health, 42: 352-359.

Evans, J.F. \& Policella, E. 2000. Changing and growing as teachers and learners: A shared journey. Teacher Education Quarterly. Summer: 55-70.

Facebook. 2009. Facebook press room statistics. http://www.facebook.com/press/info.php?statistics. Accessed on 20 October 2012.

Fine, M. \& McClelland, S.I. 2006. Sexuality education and desire: Still missing after all these years. Harvard Educational Review, 76(3): 297-338.

Francis, D. A. \& DePalma, R. 2013. Teacher perspectives on abstinence and safe sex education in South Africa. Sex Education, DOI: 10.1080/14681811.2013.833091.

Francis, D.A. 2010. Sexuality education in South Africa: Three essential questions. International Journal of Educational Development, 30(3): 314-319.

Francis, D. \& Ingram-Starrs, L. 2005. The labour of learning to reflect. Teachers and Teaching:Theory and Practice, 11(6): 541-553.

Goldman, J. 2008. Responding to parental objections to school sexuality education: A selection of 12 objections. Sex Education, 8(4): 415-438.

Henning, E., Van Rensburg, W \& Smit, B. 2004. Finding your way in qualitative reseach. Pretoria: Van Schaik

IT NEWS Africa. 2012. Social media breaks barriers in South Africa. http://www.itnewsafrica.com/2012/09/social-media-breaks-barriers-in-south-africa/. Accessed on 13 November 2012.

Kirby, D., Laris, B.A. \& Rolleri, L. 2005. Impact of sex and HIV education programs on sexual behaviours of youth in developing and developed countries. Youth Research Working Paper no. 2. Research Triangle Park, NC: Family Health International.

Mankoff, J., Matthews, D., Fussel, S.R. \& Johnson, M. 2007. Leveraging social networks to motivate individuals to reduce their ecological footprints. Proceedings of the $40^{\text {th }}$ Hawaii International Conference on System Sciences. DOI 
http://doi.ieeecomputersociety.org/10.1109/HICSS.2007.325. Accessed on 27 October 2012.

Morse, J.M. \& Field, P.A. 1998. Nursing research of qualitative approaches. Cheltenham: Stanley Thornes.

Nielsen report. 2009. State of the media: Social Media Report Q3. http://www.nielsen.com/us/en/insights/reports-downloads/2011/social-media-reportq3.html. Accessed on 3 November 2012.

Passy, F. \& Giugni, M. 2001. Social networks and individuals perceptions: Explaining differential participation in social movements. Sociological Forum, 16(1): 123-153.

Rogow, D. \& Haberland, N. 2005. Sexuality and relationships education: Toward a social studies approach. Sex Education, 5(4): 33-44.

Shön, D. 1983. The reflective practitioner: How professionals think in action. New York: Basic Books.

Strange, V., Forrest, S., Oakley, A., Stephenson, J. And the RIPPLE study team. 2006. Sex and relationship education for 13 - 16 year olds: evidence from England. Sex Education, 6(1): 31-46.

Strauss, A. \& Corbin, J. 1998. Basics of qualitative research. Techniques and procedures for developing grounded theory. London: Sage.

Thomas, G. 2009. How to do your research project: A guide for students in education and applied social sciences. London: Sage Publications.

UNAIDS 2011. Factsheet: Women, girls, gender equality and HIV. http://www.unaids.org/en/media/unaids/contentassets/documents/factsheet/2012/20 120217_FS_WomenGirls_en.pdf. Accessed on 12 November 2012.

UNICEF 2011. From 'What's your ASLR' to 'Do you wanna go private?' www.unicef.org/southafrica/media_9718.html. Accessed on 14 November 2012.

UNICEF 2012. South African mobile generation. Study on South African young people on mobiles. $\quad$ www.unicef.org/southafrica/SAF_resources_mobilegeneration.pdf. Accessed on 2 November 2012.

Winkleby, M.A., Feighery, E., Dunn, M., Kole, S., Ahn, D. \& Killen, J. 2004. Effects of an advocacy intervention to reduce smoking among teenagers. Archives of Pediatric $\mathcal{E}^{\circ}$ Adolescent Medicine, 158(3): 269-275.

Wood, L. (ed.) 2008. Dealing with HIV and AIDS in the classroom. Cape Town: Juta.

World Bank, 2000. Health, nutrition and population goals: reduction strategy framework. Report of a consultation. Washington D.C.

Zisser, A. \& Francis, D. 2006. Youth have a new view on AIDS, but are they talking about it? African Journal of AIDS Research, 5(2), 189-196. 